\title{
Personal history of rosacea and risk of incident cancer among women in the US
}

\author{
W-Q Li ${ }^{\star}, 1,2$, M Zhang $^{3}$, F W Danby ${ }^{5}, \mathrm{~J} \mathrm{Han}^{4,6,7}$ and A A Qureshi*,1,2,4 \\ ${ }^{1}$ Department of Dermatology, Warren Alpert Medical School, Brown University, Providence, RI 02903, USA; ${ }^{2}$ Department of \\ Epidemiology, School of Public Health, Brown University, Providence, RI 02903, USA; ${ }^{3}$ Department of Dermatology, Brigham and \\ Women's Hospital, Harvard Medical School, Boston, MA 02115, USA; ${ }^{4}$ Channing Division of Network Medicine, Department of \\ Medicine, Brigham and Women's Hospital, Harvard Medical School, Boston, MA 02115, USA; ${ }^{5}$ Department of Surgery \\ (Dermatology), Geisel School of Medicine at Dartmouth, Manchester, NH 03755, USA; ${ }^{6}$ Department of Epidemiology, Richard M. \\ Fairbanks School of Public Health, Indiana University, Indianapolis, IN 46202, USA and ${ }^{7}$ Melvin and Bren Simon Cancer Center, \\ Indiana University, Indianapolis, IN 46202, USA
}

Background: Rosacea is an inflammatory skin disease. We examined the association between personal history of rosacea and risk of incident cancers.

Methods: A total of 75088 whites were included from the Nurses' Health Study II (1991-2011). Information on clinician-diagnosed rosacea and diagnosis year was collected in 2005. All cancers other than basal cell carcinoma (BCC) were confirmed.

Results: During 1447205 person-years, we identified 5194 cases with internal malignancies and 5788 with skin cancers. We did not observe significant associations between personal history of rosacea and internal malignancies, except for thyroid cancer (hazard ratio $(H R)=1.59,95 \%$ confidence interval $(C l)=1.07-2.36)$. Among skin cancers, personal history of rosacea was associated with an elevated risk of $\mathrm{BCC}(\mathrm{HR}=1.50,95 \% \mathrm{Cl}=1.35-1.67)$.

Conclusions: We suggest possible associations between personal history of rosacea and an increased risk of thyroid cancer and BCC. Further studies are warranted to replicate our findings and to explore the underlying mechanisms.

Rosacea is a chronic inflammatory cutaneous disorder. Dysfunction in the innate and (or) adaptive immune response may contribute to its pathophysiology (Elewski et al, 2011; Steinhoff et al, 2013). Genetic predisposition, ultraviolet (UV) radiation, psychological factors, Helicobacter pylori infection, and detrimental lifestyles have been proposed as possible risk factors (Elewski et al, 2011; Steinhoff et al, 2013; Tan and Berg, 2013). This raises the possibility that rosacea may be an end-organ response in a systemic disorder.

Cancer is a major systemic disorder with imbalanced inflammatory and immune response as a hallmark (Moss and Blaser, 2005). Other overlapping risk factors also suggest a possible association between rosacea and cancers. However, prior studies linking rosacea to cancers have been very sparse (Margolin, 2004; Friedman et al, 2006). We systemically examined the association between a personal history of rosacea and risk of incident cancer, based on a prospective analysis of the Nurses' Health Study II (NHS II). We comprehensively estimated the risk of the subsequent risk of internal malignancies (non-skin cancers) and skin cancers for women with rosacea.

\section{MATERIALS AND METHODS}

The NHS II began in 1989 when 116430 US female nurses aged 25-42 years, completed a baseline questionnaire on medical history and lifestyle practices (Supplementary Information). Biennially, participants received a questionnaire and a response rate exceeding $90 \%$ has been achieved in the follow-up. Among participants with information on personal history of rosacea, we excluded those with 
missing date of birth, all cancers at baseline, and all non-whites, and 75088 participants remained.

The main exposure is personal history of rosacea. In 2005, NHS II participants responded to a question on whether they had clinician-diagnosed rosacea and the diagnosis date if so (before 1991, 1991-1994, 1995-1998, 1999-2002, or 2003-2005).

Since 1989, participants have reported diagnoses of cancers, including all internal malignancies, melanoma, and skin keratinocyte carcinoma (also known as non-melanoma skin cancer, including squamous cell carcinoma (SCC) and basal cell carcinoma (BCC)), on biennial surveys. Related medical records were reviewed by physicians. Only pathologically confirmed invasive cases were included, except for breast cancer and bladder cancer, which included both invasive and in situ cases. For BCC, we did not seek to obtain the medical records for all, but previous reports have demonstrated a high validity of self-reports (Colditz et al, 1986; Hunter et al, 1992).

Statistical analysis. Person-years of follow-up were calculated from the return of the 1991 questionnaire to the date of diagnosis of the first internal (or skin) cancer, death, the last questionnaire response, or June of 2011, whichever came first.

We calculated the hazard ratios (HRs) and 95\% confidence intervals (CIs) of major individual cancer (with $>100$ incident cases) using Cox proportional hazards models, stratified by 2 -year interval. Multivariate models were adjusted a priori for age, body mass index, alcohol consumption, physical activity, physical examination, multivitamin use, smoking status, oral contraceptive use, menopausal status and postmenopausal hormone use, as well as use of medications including tetracycline, isotretinoin, and antibiotics (Supplementary information). For skin cancers and breast cancer, we additionally adjusted for related risk factors (see footnotes for Table 2 and Supplementary information). An indicator was created for the missing data of each covariate as appropriate. For individual cancers significantly associated with personal history of rosacea, we conducted additional analyses (online Supplementary Information)

Analyses were carried out by using SAS (version 9.2; SAS Institute Inc., Cary, NC, USA). All $P$-values were two-tailed with the significance level set at $P<0.05$.

\section{RESULTS}

Among 75088 women, 6015 (8.0\%) had been diagnosed with rosacea as of 2005. Of them, 1064 had rosacea diagnosed before 1991. Women with rosacea were older and more likely to be postmenopausal and have had benign breast diseases, but less likely to be current smokers or current oral contraceptive users. Rosacea cases reported less sun exposure but tended to expose more to other skin cancer risk factors. Rosacea cases also reported an increased history of severe teenage acne and use of tetracycline, isotretinoin, or antibiotics (Table 1).

A total of 5194 internal cancer cases were identified within 1447205 person-years (1991-2011, Table 2). We did not find significant association between a personal history of rosacea and risk of incident total internal malignancies ( $\mathrm{HR}=1.08,95 \%$ $\mathrm{CI}=0.96-1.22$ ). For individual cancers, a personal history of rosacea was significantly associated with increased risk of incident thyroid cancer ( $\mathrm{HR}=1.59,95 \% \mathrm{CI}=1.07-2.36)$, but not with other individual cancers. Subgroup analysis for breast cancer by subtypes or oestrogen receptor/progesterone receptor status did not reach any significant findings either. For thyroid cancer, further analyses did not change the results materially. The HRs (95\% CIs) were $1.58(1.06-2.36)$ for the analysis additionally adjusting for severe teenage acne, 1.53 (1.00-2.33) for the analysis excluding those reporting a history of severe
Table 1. Baseline characteristics of women according to history of rosacea (1991)

\begin{tabular}{|c|c|c|}
\hline \multirow[b]{2}{*}{ Characteristics $^{a}$} & \multicolumn{2}{|c|}{ Rosacea } \\
\hline & $\begin{array}{c}\text { No } \\
(n=74024)\end{array}$ & $\begin{array}{c}\text { Yes } \\
(n=1064)\end{array}$ \\
\hline Mean age, years (s.d.) & $36.2(4.7)$ & $37.6(4.1)$ \\
\hline Height, m (s.d.) & $1.6(0.1)$ & $1.7(0.1)$ \\
\hline Body mass index, $\mathrm{kg} \mathrm{m}^{-2}$ (s.d.) & $24.5(5.3)$ & $25.0(5.8)$ \\
\hline Body mass index at age $18, \mathrm{~kg} \mathrm{~m}^{-2}$ (s.d.) & $21.2(3.3)$ & $21.2(3.3)$ \\
\hline Alcohol consumption, g per week (s.d.) & $3.2(6.2)$ & $2.9(5.3)$ \\
\hline $\begin{array}{l}\text { Physical activity, metabolic equivalent } \\
\text { hours per week (s.d.) }\end{array}$ & $23.7(60.2)$ & $21.3(53.2)$ \\
\hline Multivitamin use, \% & 46.0 & 46.5 \\
\hline Physical examination, \% & 89.6 & 92.9 \\
\hline Current smoker, \% & 11.5 & 8.6 \\
\hline History of benign breast disease, $\%$ & 34.6 & 39.7 \\
\hline Family history of breast cancer, \% & 6.0 & 6.5 \\
\hline Current oral contraceptive use, \% & 10.4 & 9.5 \\
\hline Postmenopausal women, \% & 7.2 & 8.3 \\
\hline Age at menarche, years (s.d.) & $13.4(1.4)$ & $13.4(1.4)$ \\
\hline Age at first birth, years (s.d.) & $25.8(4.1)$ & $26.0(3.9)$ \\
\hline Parity among parous women, times (s.d.) & $1.6(1.2)$ & $1.5(1.2)$ \\
\hline Red or blonde hair colour, $\%$ & 20.3 & 22.9 \\
\hline $\begin{array}{l}\text { Five or more severe sunburns at ages } \\
15-20 \text { years, } \%\end{array}$ & 10.0 & 13.9 \\
\hline Childhood tendency to sunburns, $\%$ & 48.1 & 55.3 \\
\hline Three or more moles on lower legs, $\%$ & 32.4 & 36.0 \\
\hline Family history of melanoma, $\%$ & 4.4 & 5.3 \\
\hline \multicolumn{3}{|l|}{ UV index of residence $\geqslant 7$} \\
\hline $\begin{array}{l}\text { At birth } \\
\text { At age } 15 \text { years } \\
\text { At age } 30 \text { years }\end{array}$ & $\begin{array}{l}18.9 \\
19.1 \\
25.4\end{array}$ & $\begin{array}{l}20.6 \\
19.9 \\
25.8\end{array}$ \\
\hline \multicolumn{3}{|l|}{ Sun exposure $\geqslant 5 \mathrm{~h}$ per week } \\
\hline $\begin{array}{l}\text { College/high school } \\
\text { Age } 25-35 \text { years }\end{array}$ & $\begin{array}{l}60.9 \\
50.9\end{array}$ & $\begin{array}{l}58.3 \\
48.9\end{array}$ \\
\hline Personal history of severe teenage acne, $\%$ & 8.1 & 12.5 \\
\hline $\begin{array}{l}\text { Antibiotics use for treatment of acne or } \\
\text { rosacea, } \%\end{array}$ & 6.9 & 41.0 \\
\hline Tetracycline use, \% & 1.7 & 6.8 \\
\hline Isotretinoin use, \% & 1.9 & 5.0 \\
\hline
\end{tabular}

teenage acne, $1.74(1.03-2.97)$ for the analysis excluding those using medications for acne or rosacea, 1.87 (1.24-2.79) for the analysis excluding cases identified in the first follow-up period, $2.00(1.23-3.25)$ for the analysis restricting the follow-up to 2005-2011, and 1.58 (1.06-2.36) for the analysis further adjusting for history of SCC or BCC.

A total of 360 melanoma, 452 SCC, and 4976 BCC cases were documented (1991-2011). A personal history of rosacea was significantly associated with increased risk of incident BCC only $(\mathrm{HR}=1.50,95 \% \mathrm{CI}=1.35-1.67)$, but not for melanoma or SCC (Table 2). Baseline characteristics of all BCC cases identified during the follow-up according to personal history of rosacea is shown in Supplementary Table 1. Further analyses by adjusting for severe teenage acne, excluding those with severe teenage acne, excluding those using medications for acne or rosacea, excluding cases identified in the first follow-up period, or restricting the follow-up starting at 2005 did not change the results materially (data not shown). 
Table 2. Personal history of rosacea and risk of incident cancer (1991-2011)

\begin{tabular}{|c|c|c|c|c|}
\hline & No Rosacea & Rosacea & Age-adjusted RR & Multivariable-adjusted $\mathrm{RR}^{\mathrm{a}}$ \\
\hline Internal malignancies & 1382634 person-years & 64571 person-years & & \\
\hline $\begin{array}{l}\text { Breast cancer } \\
\text { Thyroid cancer } \\
\text { Endometrial cancer } \\
\text { Colorectal cancer } \\
\text { Non-Hodgkin lymphoma } \\
\text { Ovarian Cancer } \\
\text { Other internal malignancies }\end{array}$ & $\begin{array}{r}2998 \\
331 \\
255 \\
215 \\
206 \\
157 \\
720\end{array}$ & $\begin{array}{r}186 \\
29 \\
11 \\
12 \\
16 \\
11 \\
47\end{array}$ & $\begin{array}{l}1.07(0.92-1.24) \\
1.54(1.05-2.26)^{\mathrm{e}} \\
0.71(0.38-1.29) \\
0.87(0.49-1.56) \\
1.28(0.77-2.14) \\
1.15(0.62-2.13) \\
1.10(0.81-1.48)\end{array}$ & $\begin{array}{l}1.03(0.89-1.20)^{b} \\
1.59(1.07-2.36)^{e} \\
0.66(0.35-1.22) \\
0.85(0.46-1.56) \\
1.45(0.85-2.45) \\
1.18(0.63-2.23) \\
1.19(0.88-1.62)\end{array}$ \\
\hline Skin cancers ${ }^{d}$ & 1344071 person-years & 60007 person-years & & \\
\hline $\begin{array}{l}\text { Melanoma } \\
\text { Squamous cell carcinoma } \\
\text { Basal cell carcinoma }\end{array}$ & $\begin{array}{r}344 \\
418 \\
4552 \\
\end{array}$ & $\begin{array}{r}16 \\
34 \\
424\end{array}$ & $\begin{array}{l}1.04(0.63-1.72) \\
1.32(0.93-1.88) \\
1.57(1.42-1.73)^{\mathbf{e}}\end{array}$ & $\begin{array}{l}0.96(0.57-1.62) \\
1.30(0.90-1.88) \\
1.50(1.35-1.67)^{\mathbf{e}}\end{array}$ \\
\hline \multicolumn{5}{|c|}{$\begin{array}{l}\text { a Adjusted for age, body mass index (BMI), alcohol consumption, physical activity, physical examination, multivitamin use, smoking status, oral contraceptive use, menopausal status and } \\
\text { postmenopausal hormone use, as well as history of severe teenage acne, use of medications including tetracycline, isotretinoin and antibiotics. } \\
{ }^{b} \text { Additionally adjusted for personal history of benign breast disease, family history of breast cancer, age at first birth and parity, age at menarche, height, and BMI at age } 18 \text { years. } \\
{ }^{c} \text { Other individual cancers each with cases }<100 \text {. } \\
{ }^{d} \text { Additionally adjusted for natural hair colour, childhood tendency to sunburn, number of sunburns at ages } 15-20 \text { years, family history of melanoma, self-reported mole count on lower legs, sun } \\
\text { exposures at high school and at age } 25-35 \text { years, and UV index at birth, age 15, and age } 30 \text { years. } \\
{ }^{e} P<0.05 \text {. }\end{array}$} \\
\hline
\end{tabular}

\section{DISCUSSION}

We systemically examined the association between personal history of rosacea and risk of cancers during a follow-up of 20 years. Women with a personal history of rosacea had a statistically significantly elevated risk of thyroid cancer and BCC. The association remained in the models controlling for the major confounders. To our knowledge, our study is the first to reveal such associations between rosacea and thyroid cancer and BCC.

In our study, thyroid cancer is the only individual internal cancer significantly associated with rosacea. Thyroid cancer is the most common endocrine malignancy, with ionising radiation as a well-established risk factor (Boice, 2006; Li et al, 2012). Accumulating evidence demonstrates that the inflammatory response and immune function has a critical role in the pathogenesis of thyroid cancer (Bozec et al, 2010; Guarino et al, 2010). Therefore, inflammation may be one potential link between rosacea and thyroid cancer. It would be also important to examine the side effect of skin radiotherapy, which has been used for rosacea (Erceg et al, 2013).

Among skin cancers, BCC is the only one significantly associated with rosacea. It is worth noting that rosacea cases tended to have a higher UV exposure at early ages in our study. UV radiation has an important role in rosacea development (Steinhoff et al, 2013). The higher UV exposure among rosacea cases at early ages might confer an elevated risk of BCC. The non-statistically significant association in melanoma and SCC could be due to the evidence that melanoma is more sensitive to intermittent UV exposure and SCC is more sensitive to cumulative UV exposure than to exposure at early ages (Wu et al, 2014).

Rosacea and acne are chronic inflammatory skin conditions that share an inflammatory pathogenesis. Clinically, rosacea and acne are quite distinct (Fleischer, 2011). Propionibacterium acnes is connected with acne but not found to be involved in pathogenesis of rosacea. Further analyses adjusting for history of severe teenage acne or excluding those with severe teenage acne did not change the results appreciably.

Our study has the following limitations. First, there may be aetiologic heterogeneities underlying different types of rosacea. We do not have information on the subtypes of rosacea and were not able to examine the associations by rosacea subtypes. Second, all study participants were women and Caucasians. Extrapolation of our findings to men or other race/ethnicities should be approached with caution, given the potentially different types of rosacea.
Third, our study is a prospective-retrospective mixed cohort study. The self-reported personal history of rosacea in 2005 may have introduced recall bias regarding the diagnosis. However, additional analyses yielded robust findings. Moreover, because the participants are health professionals, a high validity of the rosacea selfreport is expected. Fourth, we did not seek for the medical records for all BCC cases. However, the high levels of education and familiarity with medical issues among the cohort members allows high-quality and valid information to be collected on selfadministered forms. A previous validation study showed a confirmation rate of $96 \%$ for BCC self-reports by histopathological findings or medical records among a subgroup of women in NHS (Colditz et al, 1986). Therefore, misclassification in BCC would be expected to be minimal and would not bias any association materially. The findings for BCC remained fairly robust in the different sets of analysis, such as the lag analysis excluding the first follow-up period and the analysis restricting the follow-up to 2005 and later. Therefore, the validity of the study findings was assuring. Fifth, we do not have information on other therapies for rosacea other than major medications, and are not able to evaluate the possible effects of other treatment strategies, such as radiotherapy. Sixth, we do not have access to the detailed histopathological characteristics of thyroid cancer and therefore cannot explore in depth the association with subtypes. Seventh, the concern over multiple comparisons cannot be fully addressed.

In conclusion, our data suggest possible associations between personal history of rosacea and an increased risk of thyroid cancer and BCC. We provide evidence demonstrating that rosacea may represent a systemic disorder beyond a skin condition. Further studies are required to replicate our findings in other populations, particularly those of women and non-Caucasians. It would be critical to explore the potential heterogeneities for the association with cancer in different subtypes of rosacea. Studies are warranted to explore the underlying mechanisms for our findings. For example, taking advantage of genome-wide association study and next-generation sequencing techniques would be important to identify potentially common genetic predisposition for inflammatory skin disorders and cancers.

\section{ACKNOWLEDGEMENTS}

We would like to thank the participants and staff of NHS II, for their valuable contributions as well as the following state cancer registries for their help: AL, AZ, AR, CA, CO, CT, DE, FL, GA, ID, 
IL, IN, IA, KY, LA, ME, MD, MA, MI, NE, NH, NJ, NY, NC, ND, $\mathrm{OH}, \mathrm{OK}, \mathrm{OR}, \mathrm{PA}, \mathrm{RI}, \mathrm{SC}, \mathrm{TN}, \mathrm{TX}, \mathrm{VA}, \mathrm{WA}$, and WY (states of USA). We assume full responsibility for analyses and interpretation of these data. This work was supported by Department of Dermatology, Brown University Department of Dermatology, and Nurses' Health Study II grant (UM1 CA176726). The funders had no role in study design, data collection and analysis, decision to publish, or preparation of the manuscript.

\section{CONFLICT OF INTEREST}

Dr FWD has stock with Kane Biotech, and is consultant for Abbvie, and volunteer for Hidradenitis Suppurativa Foundation, Inc. The other authors declared no conflict of interest.

\section{AUTHOR CONTRIBUTIONS}

W-QL involved in study concept and design; statistical analysis; analysis and interpretation of data; drafting of the manuscript; critical revision of the manuscript for important intellectual content; MZ involved in study concept and design; acquisition of data; critical revision of the manuscript for important intellectual content; FWD involved in acquisition of data, critical revision of the manuscript for important intellectual content; $\mathrm{JH}$ involved in study concept and design; acquisition of data; critical revision of the manuscript for important intellectual content; funding support; study supervision; AAQ involved in study concept and design; acquisition of data; drafting of the manuscript; critical revision of the manuscript for important intellectual content; funding support; study supervision.

\section{REFERENCES}

Boice Jr JD (2006) Thyroid disease 60 years after Hiroshima and 20 years after Chernobyl. JAMA 295(9): 1060-1062.
Bozec A, Lassalle S, Hofman V, Ilie M, Santini J, Hofman P (2010) The thyroid gland: a crossroad in inflammation-induced carcinoma? An ongoing debate with new therapeutic potential. Curr Med Chem 17(30): 3449-3461.

Colditz GA, Martin P, Stampfer MJ, Willett WC, Sampson L, Rosner B, Hennekens CH, Speizer FE (1986) Validation of questionnaire information on risk factors and disease outcomes in a prospective cohort study of women. Am J Epidemiol 123(5): 894-900.

Elewski BE, Draelos Z, Dreno B, Jansen T, Layton A, Picardo M (2011) Rosacea - global diversity and optimized outcome: proposed international consensus from the Rosacea International Expert Group. Journal of the European Academy of Dermatology and Venereology: JEADV 25(2): 188-200.

Erceg A, de Jong EM, van de Kerkhof PC, Seyger MM (2013) The efficacy of pulsed dye laser treatment for inflammatory skin diseases: a systematic review. J Am Acad Dermatol 69(4): 609-615 e8.

Fleischer AB Jr (2011) Inflammation in rosacea and acne: Implications for patient care. J Drugs Dermatol 10(6): 614-620.

Friedman GD, Oestreicher N, Chan J, Quesenberry Jr CP, Udaltsova N, Habel LA (2006) Antibiotics and risk of breast cancer: up to 9 years of follow-up of 2.1 million women. Cancer Epidemiol Biomarkers Prev 15(11): 2102-2106.

Guarino V, Castellone MD, Avilla E, Melillo RM (2010) Thyroid cancer and inflammation. Mol Cell Endocrinol 321(1): 94-102.

Hunter DJ, Colditz GA, Stampfer MJ, Rosner B, Willett WC, Speizer FE (1992) Diet and risk of basal cell carcinoma of the skin in a prospective cohort of women. Ann Epidemiol 2(3): 231-239.

Li J, Cone JE, Kahn AR, Brackbill RM, Farfel MR, Greene CM, Hadler JL, Stayner LT, Stellman SD (2012) Association between World Trade Center exposure and excess cancer risk. JAMA 308(23): 2479-2488.

Margolin L (2004) Severe rosacea associated with colon cancer recurrence. Int J Dermatol 43(3): 213-214.

Moss SF, Blaser MJ (2005) Mechanisms of disease: Inflammation and the origins of cancer. Nat Clin Pract Oncol 2(2): 90-97, quiz 1 p following 113.

Steinhoff M, Schauber J, Leyden JJ (2013) New insights into rosacea pathophysiology: a review of recent findings. J Am Acad Dermatol 69(6 Suppl 1): S15-S26.

Tan J, Berg M (2013) Rosacea: current state of epidemiology. J Am Acad Dermatol 69(6 Suppl 1): S27-S35.

Wu S, Han J, Vleugels RA, Puett R, Laden F, Hunter DJ, Qureshi AA (2014) Cumulative ultraviolet radiation flux in adulthood and risk of incident skin cancers in women. Br J Cancer 110(7): 1855-1861.

Supplementary Information accompanies this paper on British Journal of Cancer website (http://www.nature.com/bjc) 